\title{
A Comparison of Effectiveness of Efavirenz and Nevirapine - Based First- Line HIV Treatment in Patients Attending Coast Provincial General Hospital, Kenya
}

\author{
Article by Philip K. Naluande ${ }^{1}$, Michael M. Gicheru ${ }^{2}$, Michael F. Otieno ${ }^{3}$ \\ ${ }^{1}$ Clinical and Laboratory Standards Institute (CLSI-AFRICA), Kenya \\ ${ }^{2}$ Kenyatta University-Department of Medical Laboratory Sciences \\ ${ }^{3}$ Kenyatta University - Department of Zoological Sciences \\ E-mail:pnaluande@yahoo.com
}

\begin{abstract}
Disclaimer
The findings and conclusions in this article are those of the authors and do not necessarily represent the views of the Kenyatta University nor Clinical and Laboratory Standards Institute. Use of trade names is for identification purposes only and does not constitute endorsement by Kenyatta University nor Clinical and Laboratory Standards Institute.
\end{abstract}

\begin{abstract}
The objective of this study was to compare the effectiveness of Efavirenz and Nevirapine based Firstline HIV treatment in patients attending comprehensive care centre in Mombasa. This was a prospective comparative study. The target population was HIV positive adult patients eligible for HAART. A total of 251 patients were enrolled in the study and followed up for 12 months. All ARV naive patients with CD4 count < 350/ul with WHO stage 3 or 4 and eligible for HAART were randomly into Efavirenz and Nevirapine based regimens (D4T/3TC/EFV and D4T/3TC/NVP) and followed up for a period of twelve months. Laboratory tests were done for each patient every three months by testing for Haemoglobin, Liver enzyme test (ALT), Creatinine and CD4 cell count. The study showed that first-line regimens of Efavirenz and Nevirapine were effective in suppressing HIV/AIDS infection with improvement in CD4 count $(P<0.05)$. There was also improvement in haemoglobin levels and body weight among the patients on both regimens in the study. However, elevation of ALT and Creatinine were noted in both treatment groups, but this did not warrant drug discontinuation $(P>0.05)$. Efavirenz based regimen appeared to be superior to Nevirapine based regimen on $C D 4+$ profiles and renal function $(P<0.05)$. There was no significant difference in haemoglobin levels, body weight and ALT enzyme for patients on both treatment groups.The findings demonstrated that D4TC/3TC/EFV and D4TC/3TC/NVP combinations were safe, well tolerated and effective in suppressing HIV progression in advanced HIV infected patients.
\end{abstract}

\section{Acronyms and abbreviations}

$\begin{array}{lll}\text { AE } & : & \text { Adverse Event } \\ \text { AIDS } & : & \begin{array}{l}\text { Acquired Immune Deficiency } \\ \text { Ayndrome }\end{array} \\ \text { ALT } & : & \text { Alanine aminotransferase } \\ \text { ART } & : & \text { Antiretroviral therapy } \\ \text { ARV } & : & \text { Antiretroviral } \\ \text { CCC } & : & \text { Comprehensive Care Centre } \\ \text { CD4+ } & : & \text { Cluster of Differentiation } \\ \text { CPGH } & : & \text { Coast Province General } \\ \text { CNS } & : & \text { Central Nervous System }\end{array}$


DOI: 10.21522/TIJCR.2014.04.02.Art001

ISSN: 2520-3096

\begin{tabular}{|c|c|c|}
\hline CRF & $:$ & Case Record Form \\
\hline D4T & $:$ & Stavudine \\
\hline DNA & : & Deoxyribonucleic acid \\
\hline EDTA & $:$ & $\begin{array}{l}\text { Ethyline diamine tetraacetic } \\
\text { acid }\end{array}$ \\
\hline EFV & : & Efavirenz \\
\hline ELISA & $:$ & $\begin{array}{l}\text { Enzyme-Linked } \\
\text { Immunosorbent Assay }\end{array}$ \\
\hline FHI & $:$ & Family Health International \\
\hline FSC & $:$ & Forward Scatter \\
\hline $\begin{array}{l}\text { HAAR } \\
\text { T }\end{array}$ & $:$ & $\begin{array}{l}\text { Highly Active Antiretroviral } \\
\text { Therapy }\end{array}$ \\
\hline HIV-1 & $:$ & $\begin{array}{l}\text { Human immunodeficiency } \\
\text { virus (type- 1) }\end{array}$ \\
\hline $\mathbf{H b}$ & : & Hemoglobin \\
\hline KAPR & $:$ & Kenya AIDS Progress Report \\
\hline KDHS & : & $\begin{array}{l}\text { Kenya Demographic Health } \\
\text { Survey }\end{array}$ \\
\hline KNBS & $:$ & $\begin{array}{l}\text { Kenya National Bureau of } \\
\text { Statistics }\end{array}$ \\
\hline LFT's & : & Liver Function Tests \\
\hline 3TC & $:$ & Lamivudine \\
\hline МОН & : & Ministry Of Health \\
\hline MTCT & $:$ & Mother to Child Transmission \\
\hline NASC & : & National AIDS and STI \\
\hline $\mathbf{O P}$ & & Control Program \\
\hline NCST & $:$ & $\begin{array}{l}\text { National Council for Science } \\
\text { and Technology }\end{array}$ \\
\hline NRTI & $:$ & $\begin{array}{l}\text { Nucleoside Reverse } \\
\text { Transcriptase Inhibitor }\end{array}$ \\
\hline NNRTI & $:$ & $\begin{array}{l}\text { Non- Nucleoside Reverse } \\
\text { Transcriptase Inhibitor }\end{array}$ \\
\hline NVP & : & Nevirapine \\
\hline OI & $:$ & Opportunistic Infection \\
\hline PI & : & Protease Inhibitor \\
\hline PMCT & $:$ & $\begin{array}{l}\text { Prevention of Mother -to - } \\
\text { Child - Transmission }\end{array}$ \\
\hline SAE & $:$ & Severe Adverse Effects \\
\hline SDI & : & Standard Deviation \\
\hline SGPT & $:$ & $\begin{array}{l}\text { Serum Glutamate Pyruvate } \\
\text { Transaminase }\end{array}$ \\
\hline SSC & $:$ & Side Scatter \\
\hline STI & $:$ & Sexual Transmitted Infection \\
\hline UKNE & $:$ & United Kingdom National \\
\hline QAS & & $\begin{array}{l}\text { External Quality Assurance } \\
\text { Scheme }\end{array}$ \\
\hline ULN & • & Upper Limit of Normal \\
\hline $\begin{array}{l}\text { UNAID } \\
\text { S }\end{array}$ & : & $\begin{array}{l}\text { United Nations Program on } \\
\text { AIDS }\end{array}$ \\
\hline
\end{tabular}




$\begin{array}{lll}\text { VCT } & : & \begin{array}{l}\text { Voluntary Counselling and } \\ \text { Testing (for HIV) }\end{array} \\ \text { WHO } & : & \text { World Health Organization. } \\ \text { WBC } & : & \text { White Blood Cell Count }\end{array}$

\section{Introduction}

\section{Background information}

Antiretroviral have been widely used in developing countries, yet little has been done to find out the treatment outcome of these drugs by assessing the immunological and virological parameters of an individual's immune system in relation to the clinical response. Hence, it is important to follow the progression of HIV/AIDS patients through laboratory monitoring, as well as to review the acceptability and tolerability of ARV's which contribute to adherence, as this will help in treatment decisions by vclinicians as they can decide to continue treatment, change a particular regimen or discontinue therapy at the appropriate time. This decision will often be based on the occurrence of side effects, or increased toxicity or non-adherence to antiretroviral drugs. ART has significant toxicity that requires monitoring. Laboratory tests performed on a regular basis are usually used to detect severe toxicity, before it becomes clinically apparent and harmful. These tests, however, are costly and require patient visits, phlebotomy and appropriate infrastructure and equipment.

\section{Limitations}

The most important limitation in the study was the exclusion of co-morbidities and opportunistic infections like tuberculosis, which can induce important selection bias.

Secondly, lack of viral load testing was also another limitation of the study considering that viral load detection in blood is a good indicator of viral suppression and drug effectiveness. Thirdly, another limitation was the lack of calculation of body mass index (BMI) as an important anthropometric measurement to assess nutrition status of patients on HAART.

\section{Materials and methods}

\section{Study site}

The study was carried out in Mombasa County at the Coast Provincial General Hospital (CPGH). The County has approximately 939,370 people (KNBS, 2009) and is a Cosmopolitan Centre with a balanced population of both the youth and older people. The Centre was selected because it offered free services sponsored by Family Health International (FHI) and Ministry of Health (MOH) to all willing clients for Voluntary Counseling and Testing Services, and also that it formed the bulk of population of Mombasa District.

\section{Research design}

A Prospective longitudinal cohort study of HAART regimens given to ARV naïve HIV infected adult patients at Coast Provincial General Hospital. Clients were randomised into Efavirenz and Nevirapine based regimens (D4T /3TC / EFV and D4T /3TC / NVP) and followed up for a period of twelve months. Screening of patients was done at the Comprehensive Care Centre (CCC) after being refered from VCT clinics, outpatient clinics and the wards. Patients were then screened for eligibility criteria which included laboratory examination for liver enzymes, hemoglobin, renal function, CD4 Cell count and clinical assessments by the clinician. Patients who were eligible for HAART based on their CD4 count as per eligibility criteria were selected to be part of the study and followed up to one year (12 months). 
DOI: 10.21522/TIJCR.2014.04.02.Art001

ISSN: $2520-3096$

\section{Data collection technique}

\section{Laboratory measurements}

Ten (10) mls of blood were obtained for Haemoglobin, CD4 count and also for Liver enzyme assay (ALT) and Creatinine at baseline, 3 months, 6 months, 9 months and 12 months duration. Enzyme Linked Immunosorbent Assay (ELISA) test for HIV was used to confirm HIV positive status. Whole blood sample drawn in EDTA containing tubes was used to determine T-helper cells (CD4 count). Absolute numbers of CD4 was calculated as well as white blood cell count using the coulter counter as per manufacturer's instructions. Biochemical parameters which include Liver enzyme test (ALT) were used to assess the liver response in patients treated with ARV's by determining the values of these parameters at baseline and at intervals of three (3) months after commencement of ARV therapy for up to one year.

\section{Statistical analysis}

Data analysis was done using SPSS Version 11.0 statistical software. Basic characteristics of the study samples were summarised using simple proportions and means, median and inter quartile ranges. Further analysis was done to perform one way ANOVA comparing more than two means followed by Post hoc Student Newman Keul for multiple comparisons. Independent t-test was used to calculate if there was any significant difference between the two treatments. Study subjects were followed from HAART initiation to the earliest of death, loss to follow up, development of toxicity or end of twelve months.

\section{Results}

\section{Analysis of Patients body weight}

Body weight increased for both of the two treatment groups after initiating antiretroviral therapy for the first six months (Table 4.1) and tapered over time between 6 months and 9 months period for the two treatment groups. The mean weight increased between $9^{\text {th }}$ month and $12^{\text {th }}$ month $(1$ year) period with a mean of $62.1 \mathrm{~kg} \mathrm{95 \%} \mathrm{CI} \mathrm{(60.6} \mathrm{-} \mathrm{63.5)} \mathrm{compared} \mathrm{to} \mathrm{baseline} \mathrm{which} \mathrm{was} 55.6 \mathrm{~kg}$ ( 95\% CI 54.1- 57.1. The average increase in body weight for patients on EFV over the 12 months period was $2.2 \mathrm{~kg}$ whereas for patients on NVP was less than $2 \mathrm{~kg}$. There was no significant difference on the body weight for both patients on EFV and NVP groups $p>0.05$ as measured at 6 months. However, patients in both treatment groups experienced slight increase in weight between the $9^{\text {th }}$ month and $12^{\text {th }}$ month follow up period respectively.

Table 4.1. Body weight in kilograms of patients in the EFV and NVP study groups

\begin{tabular}{|l|l|l|l|}
\hline Time in months & Efavirenz & Nevirapine & $\boldsymbol{p}$ - value \\
\hline 0 months & $56.21 \pm 12.59$ & $54.75 \pm 10.38$ & 0.347 \\
\hline 3 months & $57.49 \pm 12.29$ & $56.48 \pm 10.18$ & 0.504 \\
\hline 6 months & $59.18 \pm 12.31$ & $58.80 \pm 10.00$ & 0.797 \\
\hline 9 months & $59.49 \pm 12.29$ & $58.30 \pm 10.29$ & 0.432 \\
\hline & & & \\
12 months & $62.49 \pm 12.29$ & $61.30 \pm 10.29$ & 0.432 \\
\hline
\end{tabular}

\section{Immunological changes}

Immunological variables were measured on a maximum of 5 occasions. There were significant differences in CD4 lymphocyte subsets between patients on EFV and patients on NVP treatment arm ( $p$ $<0.01)$ at the $6^{\text {th }}, 9^{\text {th }}$ and $12^{\text {th }}$ month respectively. 
The profiles of these values showed that EFV based regimen was superior in improvement of CD4+ count compared to NVP based regimen as shown in Table 4.2 below.

Table 4.2. Mean CD4 + cells for patients in the study CD4 + Cells/mm3

\begin{tabular}{|l|l|l|l|}
\hline Time in months & Efavirenz & Nevirapine & $\boldsymbol{p}$-value \\
\hline & & & \\
0 months & $133.75 \pm 91.98$ & $165.11 \pm 61.33$ & 0.001 \\
\hline 3 months & $171.32 \pm 103.38$ & $139.74 \pm 63.65$ & 0.003 \\
\hline 6 months & $200.07 \pm 114.28$ & $161.39 \pm 68.33$ & 0.001 \\
\hline 9 months & $270.07 \pm 114.28$ & $231.39 \pm 68.33$ & 0.001 \\
\hline & & & \\
12 months & $365.07 \pm 114.28$ & $326.39 \pm 68.33$ & 0.001 \\
\hline
\end{tabular}

The comparison of differences in immunological parameters between the baseline period, 3 months, 6 months, 9 months and 12 months for both EFV and NVP patients are well illustrated in table 4.2 above. The means of the differences between changes for EFV and NVP were significantly different $(p<0.001)$. The data on CD4 count confirm that patients at enrolment had lower levels of CD4 cell count at the onset of the study for both groups. In addition, the data indicate that the mean absolute numbers of CD4 count were slightly higher for the patients on NVP regimen compared to EFV regimen at the baseline with means of 165.11 (103.78 - 226.44) and 133.75 (41.77 - 225.73) respectively. The mean absolute CD4 cell count for patients on both regimens increased to the $12^{\text {th }}$ month period suggesting positive immune response following HAART therapy. During the first 6 months of ART, the number of CD4+ T cells typically increased by 30 cells to 60 cells $/ \mathrm{mm}^{3}$ of blood. This burst was then followed by a second, faster phase of $\mathrm{T}$ cell repopulation with an average rate increase of 70 cells $/ \mathrm{mm}^{3}$ in the $9^{\text {th }}$ month of ART.

\section{Hemoglobin levels during the study period}

Hemoglobin levels increased for patients in both arms of treatment (EFV and NVP) group up to the $6^{\text {th }}$ month. However, there was a sudden decline of hemoglobin levels towards the $9^{\text {th }}$ month. Hemoglobin levels increased further from $9^{\text {th }}$ month to $12^{\text {th }}$ month during the study. There was no significant difference in haemoglobin levels of patients on EFV and NVP regimens throughout the study $(p>0.05)$ (Table 4.3).

Table 4.3. Mean of hemoglobin $(\mathrm{g} / \mathrm{dl})$ during the 12 months study period

\begin{tabular}{|l|l|l|l|}
\hline Time in months & Efavirenz & Nevirapine & $\boldsymbol{p}$-value \\
\hline 0 months & $10.49 \pm 2.40$ & $10.03 \pm 2.29$ & 0.135 \\
\hline 3 months & $11.18 \pm 2.39$ & $10.92 \pm 2.30$ & 0.406 \\
\hline 6 months & $11.88 \pm 2.52$ & $11.82 \pm 2.39$ & 0.858 \\
\hline 9 months & $11.58 \pm 2.39$ & $11.33 \pm 2.33$ & 0.145 \\
\hline 12 months & $11.98 \pm 2.39$ & $11.73 \pm 2.35$ & 0.420 \\
\hline
\end{tabular}

Reference ranges for Hemoglobin: Adult Male: $13.0 \mathrm{~g} / \mathrm{dl}$ - $18.0 \mathrm{~g} / \mathrm{dl}$ and Adult Female: $12.0 \mathrm{~g} / \mathrm{dl}$ $15.0 \mathrm{~g} / \mathrm{dl}$ 
DOI: 10.21522/TIJCR.2014.04.02.Art001

ISSN: $2520-3096$

\section{Liver enzymes (ALT) before and after initiation of HAART}

The monitoring of patients through the two ARV regimens allowed the analysis to be done for toxicity. There was no significant difference in the mean values of ALT enzymes for patients on EFV based regimen and NVP based regimen from baseline to the $12^{\text {th }}$ month $(p>0.05)$. Nevertheless, the hepatic biological tolerance during EFV or NVP based regimen was generally good in months 3 and 6 . The majority of the mean values of ALT enzymes studied were above normal ranges except for those at baseline (Table 4.4).

Table 4.4. Mean liver enzymes alt (U/L) for patients during the study

\begin{tabular}{|l|l|l|l|}
\hline Time in months & Efavirenz & Nevirapine & $\boldsymbol{p}$-value \\
\hline 0 months & $49.81 \pm 3.48$ & $44.83 \pm 4.40$ & 0.379 \\
\hline & & & \\
3 months & $67.86 \pm 5.13$ & $62.39 \pm 5.29$ & 0.485 \\
\hline 6 months & $85.80 \pm 9.21$ & $90.38 \pm 14.55$ & 0.780 \\
\hline & & & \\
9 months & $126.57 \pm 12.13$ & $137.89 \pm 21.40$ & 0.620 \\
\hline & & & \\
12 months & $165.99 \pm 18.30$ & $183.32 \pm 31.09$ & 0.608 \\
\hline
\end{tabular}

Reference ranges for ALT enzyme: Adult Male and Female: $7 \mathrm{U} / \mathrm{L}-55 \mathrm{U} / \mathrm{L}$.

The comparison of ALT enzymes after initiation of HAART has shown that changes in these parameters were similar in both HAART regimens. The early hepatic biological tolerance during EFV or NVP based regimen was generally good and similar. However, significant increases in the enzyme values for ALT were observed with the NVP based regimen when compared with EFV regimen. There were also 16 cases of clinical toxicities which later resolved. Ten were associated with Stavudine and Nevirapine with mainly peripheral neuropathy, lipodostrophy and CNS symptoms.

\section{Creatinine trends of patients in the study}

The Creatinine levels increased minimally for all patients from onset of ARV's up to a maximum of $154 \mathrm{umol} / \mathrm{L}$ at the end of the follow up. There was significant difference of Creatinine levels for the two regimens with Nevirapine giving higher values than Efavirenz regimen ( $\mathrm{p}<0.001$ ). (Table 4.5).At endpoint patients on EFV regimen had Creatinine mean of $135.61 \pm 0.89$ compared to NVP mean of 151.04 \pm 3.30 . However, none of the patients reached a Creatinine level of $>300 \mathrm{umol} / \mathrm{L}$ to warrant drug discontinuation or regimen change.

Table 4.5. Mean creatinine levels (umol/L) for patients on EFV and NVP

\begin{tabular}{|l|l|l|l|}
\hline Time in months & Efavirenz & Nevirapine & $\boldsymbol{p}$-value \\
\hline 0 & $74.16 \pm 2.60$ & $75.19 \pm 3.37$ & 0.808 \\
\hline 3 & & & 0.405 \\
\hline & $91.47 \pm 1.51$ & $94.49 \pm 3.29$ & \\
\hline & & & 0.036 \\
\hline
\end{tabular}




\begin{tabular}{|l|l|l|l|}
\hline & & & 0.003 \\
\hline & $128.81 \pm 1.02$ & $137.08 \pm 3.11$ & \\
\hline 12 & $135.61 \pm 0.89$ & $151.04 \pm 3.30$ & $<0.001$ \\
\hline
\end{tabular}

Reference ranges for Creatinine: Adult Male: $80.0 \mathrm{U} / \mathrm{L}$ - 115.0 U/L and Adult Female: 53.0 U/L - 97.0 $\mathrm{U} / \mathrm{L}$

\section{Discussion}

\section{Effect of HAART on CD4 profiles}

The study has demonstrated clinical benefits in terms of CD4 cell count and weight increase well into the end of first year of follow up. The finding of a rapid rise in CD4 cell counts during the initial few weeks of therapy followed by a slower rise for the patients in the current study are consistent with earlier reports on CD4 cell kinetics conducted in the USA. In addition, the mean CD4 cell increase seen in patients in this study at one year after antiretroviral therapy initiation is similar to the response seen in studies conducted in Europe (Lifson et al., 2011). As such, the mean CD4 cell increase seen at later time periods reflect responses to both primary and secondary regimens (about $10 \%$ of the patients in the study switched to second line therapy). Alternatively, individuals in the current study may have different hepatic regeneration capacities at the initiation of ART. For this study population, $\mathrm{CD}^{+}$cells had continued to increase up to 12 th month period.

In fact, even among highly advanced patients in our study who initiated HAART with CD4 cell counts below 200 cells/mm3, subsequent increase in CD4 cell count was most strongly predicted following treatment with HAART. Previous studies showing that CD4 cell counts $<350$ cells/mm3 may preclude a CD4 cell count response may have been confounded by patient non adherence (Kenneth et al., 2013).

The main immunologic outcome observed was the change in CD4 cell count over time. A switch in therapy occurred if the ART regimen recorded at follow up was different from the regimen initially started. Any individual drug substitution or regimen change was considered a switch. Dose reduction however, was not considered an ART switch. The time of the first switch defined the time of reaching the outcome. If the physician recorded a symptom during a clinic visit believed to be attributed to ART, a toxicity event was considered to have occurred.

Deaths were recorded based on physicians or family notification on the discontinuation. Official records such as death certificates were not usually available. The primary end point was mortality from all cases in the 12 months after starting HAART. Changes in CD4+ cell counts in the first 3, 6, 9 and 12 months were secondary end point measurements used in this analysis. Time was measured from the start of HAART and ended at the earliest of the date of death, the date of the last follow up visit or month 12 after starting HAART.

\section{Effect of HAART on body weight changes}

The current study found that mean body weight gains mirrored CD4 cell increase immediately following antiretroviral therapy initiation and this correlated with the findings of Barnejee et al. (2010) which showed that HAART had a positive effect on growth in HIV 1 infected individuals. HAART had modestly favourable effects on body composition, particularly in patients with greater pretreatment immunosuppression and virological suppression. In a previous study HIV-1 infected individuals and especially children experienced a continued gain in body weight after starting HAART (Denue et al., 2013). However, body weight was found to have subject variability with consistent mean body weight increases among the NVP based and EFV based treatment arms in the study period. 
DOI: 10.21522/TIJCR.2014.04.02.Art001

ISSN: $2520-3096$

\section{Effect of HAART on liver enzyme (ALT)}

All HAART drugs have a potential of causing severe hepatotoxicity (Adikwu et al., 2013). The results of this study tie with those obtained by another study by Lucien et al. (2010) which showed that HAART was associated with low level hepatotoxicity at therapy initiation, regardless of drug class. The lack of significant difference in the proportion of patients who experienced an increased enzyme activity between these two ARVs regimens could be due to the fact that Stavudine toxicity present on both arms of treatment could have masked the actual toxicity experienced by NVP. In another related study, patients who have been on HAART had significantly elevated ALT and AST levels but mild toxicity (Shakirat et al., 2014). Our study was also comparable with that of Kalyesubula et al. (2011) who in their retrospective cohort study determined the incidence of hepatotoxicity associated with (NNRTI) in a group of HIV infected patients who received EFV and NVP and the rate was similar among the treatment groups.

The findings in the current study were also comparable to those of Emily et al. 2010 who showed in a study on liver injury after receiving Nevirapine; that elevated liver enzymes was observed in their cohort. Other studies that showed similar results with our study are those on early hepatotoxicity during the first 12 weeks of treatment (Adikwu et al., 2013). In their analysis, the frequency of hepatotoxicity was $17 \%$ in the group receiving NVP and $0 \%$ in the EFV group. In another related study, data confirmed an increased risk of early hepatotoxicity associated with the use of NVP (Shakirat et al., 2014). The proportion of patients who had elevated ALT activity had tripled with each ARV therapy from month 3 to month 6. The increased activity of ALT was reported as a potential side effect of most ARVs used in the treatment of HIV infection. Kalyesubula et al. (2011) concluded in their study that hepatotoxicity occurs during HAART therapy and was more common in patients receiving NVP than those using EFV which is consistent with results of this study.

It has been reported in another study by Lucien et al., (2010) that some patients who experienced serious liver toxicity with NVP did not develop hepatotoxicity during subsequent treatment with EFV, suggesting that toxicity was related to ARV and not to specific class (Lucien et al., 2010). The high incidence rate of severe hepatotoxicity in the first 3 months of initiating ART necessitates the need for more frequent and careful monitoring of ALT levels early during therapy.

\section{Effect of HAART on renal function}

In our study, none of the patients had renal failure but the study showed that closer monitoring of renal function is essential in all HIV patients on HAART. This result is consistent with the study of Mainasara et al. (2014) which showed that HAART of Stavudine, Lamivudine and Nevirapine improve renal creatinine clearance functions among the HIV positive patients. Similar results were also obtained by Robert et al. (2015) on the study of predictors of renal outcome in HIV associated nephropathy.

HAART and other medical therapies for HIV related infections have been associated with both short and long term toxicities including nephrotoxicity.

\section{Effect of HAART on haemoglobin levels}

The present findings show that there is an association between anemia, decreased survival, and increased disease progression in patients with HIV infection. In our study, low platelets counts resolved in patients on ART and were probably not drug related. Thus monitoring of hemoglobin would have been enough to detect nearly all of the significant cases of anaemia. Metabolic abnormality associated with potent antiretroviral regimens including NVP may revert at least partially with time and after replacing NVP by EFV as observed in this study. In a different study haemoglobin changes following HAART varied by sex and age, but remained significantly associated with prognosis in both sexes (Florence et al., 2011). Also studies from other developed countries suggest that use of HAART reduces the risk of anemia in patients with HIV infection and improves hemoglobin values in many patients who are already anemic at the time of HAART initiation (Simbarashe et al., 2013). Our study showed decreased anemia 
with HAART use, which supports data from prior studies which showed that patients on HAART had improved hemoglobin levels and less incidence of anaemia (Chauhan et al., 2011). Similarly, studies by Zelalem et al. (2014) found that HAART was an effective treatment for anemia of HIV infection, and the potential mechanisms that might be involved included a reduction in opportunistic infections and the anemia of chronic disease, and an improvement in nutritional status. Lower body mass index was also associated with a high risk of anemia.

\section{Conclusions}

The results from this study demonstrated that D4TC/ 3TC/ EFV and D4TC/ 3TC/ NVP combinations were safe, well tolerated and effective in increasing CD4 Cell counts and suppressing HIV progression in advanced HIV infected patients.

\section{Recommendations for future steps}

Patients with HIV should have their CD4 cell count monitored regularly before and after commencement of HAART before they reach immunological failure. The findings support the ongoing feasibility of early ART roll out in the country. Therapeutic monitoring may be a useful tool for the administration of HAART in the future. In the future, closer monitoring of renal function and adverse effects of HAART should be enhanced as these parameters appear elevated with time as patients continue to use the drugs. Renal function and Liver function should therefore be monitored on a regular basis in patients with HIV receiving any antiretroviral agent.

\section{References}

[1].Achkar, J. M. and Elizabeth, R. J. (2011). Incipient and Subclinical tuberculosis. Defining early disease states in the context of Host immune response. Journal of Infectious Diseases 204:1179 - 1186.

[2].Adikwu, E. and Brambija, N. (2013). Concentration effect, incidence and mechanism of Nevirapine hepatotoxicity. American Journal of Pharmacology and Toxicology 8:20-30.

[3].Banerjee, T., Pensi, T., and Grover, G. (2010). Impact of HAART on survival, weight gain and resting energy expenditure in HIV-1 infected children in India. Annals of Tropical Pediatrics 30: 27-37.

[4].Chauhan, N. K., Vajpayee, M. and Singh, A. (2011). Usefulness of hemoglobin and albumin as prognostic markers for highly active antiretroviral therapy for HIV- 1 infection. Indian Journal of Medical Sciences 65:286 296.

[5].Denue, B. A., Ikunaiye, P. N. Y. and Denue, C. B. A. (2013). Body mass index changes during highly active antiretroviral therapy in Nigeria. Eastern Mediterranean Health Journal 19:89-97.

[6].Emily, L. H., Mary, L. T., Kenneth, S., Amy, C. and Melissa, D.J. (2010). Incidence of severe hepatotoxicity related to antiretroviral therapy in HIV/HCV coinfected patients. Aids Research and Treatment. Accessed online at http://dx.doi.org/10.1155/2010/856542.

[7].Florence, M., Jean, B. G., Joshua, M., Doris, D. and Jan, P. (2011). Anaemia in Human immunodeficiency virus infected and uninfected women in Rwanda. American Journal of Tropical Medicine and Hygiene 84: 456 - 460

[8].Kalyesubula, R., Kagimu, M., Opio, K., Kiguba, R., Semitala, C., Schlech, W. and Katabira, E. (2011). Hepatotoxicity from first line antiretroviral therapy: an experience from a resource limited setting. Journal of African Health Sciences, 11: 16-23.

[9].Kenya AIDS Progress Report. (2014). Kenya Demograhic Health Survey. (2014).

[10].Kenya National Bureau of Statistics. (2009) Population and Housing Census, Pg. 7.

[11].Kenneth, A. A., Olumuyiwa, O., Dorothy, A., Tindak, S., Mohamed, A., Stephen, O., Rosalyn, C. K. and Anthony, K. W. (2013). Medication adherence and cluster of differenciation for CD4 Cells response in patients receiving antiretroviral therapy. Journal of AIDS and HIV Research 5:163-169.

[12].Lifson, A. R., Krautz, E. M., Eberly, L. E., Dolan, M. J., Marconi, V. C., Weintrob, A. C., Cianflora, N. F., Ganesan, A., Grambsch, P. L. and Agan, B. K. (2011). Long term CD4 lymphocyte response following HAART initiation in a US military prospective cohort. Journal of AIDS Research and Therapy 8:2 http://www.aidsrestherapy.com. 
DOI: 10.21522/TIJCR.2014.04.02.Art001

ISSN: $2520-3096$

[13].Lucien, K. F., Clement, A. N. J., Fon, N. P., Weledji, P. and Ndikvu, C. P. (2010). The Effects of antiretroviral therapy treatment on liver function enzymes among HIV infected out patients attending the Central Hospital of Yaounde Cameroon. African Journal of Clinical and Experimental Microbiology 11:3.

[14].Mainasara, A. S., Isah, B. A., Ahmed, A. Y. and Erhabor, O. (2014). Effect of highly active antiretroviral therapy (HAART) on renal functions among persons living with HIV and AIDS (PLWHA) in Sokoto, North Western Nigeria. American Journal of Pharmacy and Pharmacology 13: 23 - 27.

[15].Paolo, M., Dario, B., Paolo, B., Leonardo, C., Chiara, C., Antonio, D. B., Simone, M., Francesco, M., Vincenzo, M., Cristina, M., Pasquale, N., Stefano, R. and Fabio, V. (2012). Renal complications in HIV disease: Between present and future. AIDS Research 14: $37-53$.

[16].Robert, A. N., David, O. and George, A. (2015). Effects of HIV infection and Highly Active Antiretroviral Therapy (HAART) on the Liver of HIV patients. Trends in Medical Research 10: 1-11.

[17].Shakirat, I. B., Abel, N. O. and Patrick, O. E. (2014). Long term effect of HAART on biochemical profiles of HIV/AIDS patients in a tertiary health facility in Benin city, Nigeria. Tropical Journal of Pharmaceutical Research 11:1941 - 1946.

[18].Simbarashe, T., Mhairi, M., Alana, T. B., Ian, S., Patrick, M. and Mathew, P. F. (2013). Anaemia among HIV infected patients initiating antiretroviral therapy in South Africa: Improvement in hemoglobin regardless of degree of immunosuppression and the initiating ART regimen. Journal of Tropical Medicine 27:162950. Epub 2013 Aug 27 http://dx.doi.org/10.1155/2013/162950.

[19].World Health Organization. AIDS Epidemic Update. (2015).

[20].World Health Organization (WHO) (2007). Addendum to 2006 WHO guidelines on Antiretroviral Therapy for HIV Infection in Adults and adolescents Geneva.

[21].Zelalem, T. and Bamlaku, E. (2014). Prevalence of anaemia before and after initiation of highly active antiretroviral therapy among HIV positive patients in North West Ethiopia: A retrospective study. BMC Research Notes 7:745. 